\title{
Are the factors recommended by UNEP-SETAC for evaluating biodiversity in LCA achieving their promises: a case study of corrugated boxes produced in the US
}

\author{
Caroline Gaudreault $^{1}$ (D) Craig Loehle $^{2} \cdot$ Stephen Prisley $^{3} \cdot$ Kevin A. Solarik ${ }^{1} \cdot$ Jacob P. Verschuyl $^{4}$
}

Received: 4 July 2019 / Accepted: 3 May 2020 / Published online: 15 May 2020

(C) The Author(s) 2020

\begin{abstract}
Purpose We tested the effectiveness of the global and ecoregion-based average characterization factors (CFs) for "Potential Species Loss" recommended by the UNEP-SETAC Life Cycle Initiative to identify hotspots and improvement opportunities compared to using a land competition indicator for a product for which the predominant life cycle use of land is forest management.

Methods For a case study of average corrugated boxes produced in the US, system boundaries were defined to encompass all life cycle stages from forest management to disposal. Fiber procurement was regionalized to US ecoregions, and (Chaudhary et al. Environ Sci Technol 49:9987-9995, 2015) ecoregion-specific CFs were applied. US-average CFs were applied to other background processes. Hotspots were identified using contribution analyses, and improvement opportunities were evaluated using scenarios. We compared the results with those from applying a land competition indicator, often used as a proxy for biodiversity in LCA.

Results and discussion Forest management was identified as the activity within the life cycle of corrugated boxes that uses the greatest amount of land, allowing the definition of two potential improvement opportunities: reducing fiber consumption and intensifying forest management. By applying the recommended CFs, fiber procurement was also identified as the main contributor to "Potential Species Loss." The CFs also allowed to identify ecoregions in which species were potentially the most affected by forest management and related potential improvement opportunities. Tradeoffs between taxonomic groups were discussed. In some cases, the results contradicted those from applying a land competition indicator, and in many cases, we were unable to reconcile the results obtained with existing scientific knowledge on species diversity and forest management.

Conclusions and recommendations The results obtained by applying the recommended CFs could not always be reconciled with existing scientific knowledge on the effect of forest management on species diversity, significantly impairing the usefulness of these factors for assessing improvement opportunities and increasing the risk of counterproductive decisions. The local effect on species of forest management is likely to be misrepresented by the average number of species in a given ecoregion. Successful consideration of biodiversity response in the context of forest management would require the integration of other approaches, such as site-specific studies. Potential improvements to the proposed method include further spatialization of the CFs, defining a range of forest management practices for which CFs would be defined, considering forest productivity, and defining CFs using a baseline that would encourage better practices even within a given existing management regime.
\end{abstract}

Keywords Biodiversity $\cdot$ Ecoregion $\cdot$ Forest management $\cdot$ LCA $\cdot$ Life cycle assessment $\cdot$ UNEP-SETAC $\cdot$ Corrugated boxes $~$ United States

Responsible Editor: Jörg Schweinle

Caroline Gaudreault

cgaudreault@ncasi.org

1 NCASI, 2000 McGill College Ave, 6th Floor, Montréal, QC H3A $3 \mathrm{H} 3$, Canada

2 NCASI, 1258 Windemere Ave., Naperville, IL 60564, USA

3 NCASI, 541 Washington Ave SW, Roanoke, VA 24016, USA

4 NCASI, P.O. Box 1259, Anacortes, WA 98221, USA

\section{Introduction}

Life cycle assessment (LCA) is one of several environmental evaluation tools for characterizing environmental impacts, positive or negative, related to products and services over their full life cycle (i.e., from raw material acquisition to final disposal). One key feature of LCA is the requirement to consider a comprehensive set of environmental aspects when assessing products and services. These may include impact categories 
addressing various scales: global effects (e.g., global warming), regional effects (e.g., smog), or site-specific effects (e.g., human health effects). Impact categories addressing global and regional effects are typically well covered in LCA. However, it is still quite challenging, and it remains an issue to have meaningful LCA methods that address sitespecific effects such as those related to land use and biodiversity in LCA (Chaudhary et al. 2015; Gaudreault et al. 2016).

Using land for agriculture, mining, urban development, forestry, and other anthropogenic activities can have significant implications for biodiversity and other ecosystem services (e.g., recreation, education), and there is broad agreement that there is a need for better accounting and a clearer understanding of land use impacts in general (e.g., Chapin et al. 2000; EEA 1995; FAO 1976; Milà i Canals et al. 2007; Newbold et al. 2015; Oldemann et al. 1991; Pimentel et al. 1995). While there has been increasing interest in assessing effects associated with land use and land use changes, characterizing environmental aspects of land use associated with forest products can be challenging, especially using LCA that has not been shown to provide reliable assessments capturing the complexities of biodiversity responses to forest management (Gaudreault et al. 2016), although significant research is still underway (e.g., Côté et al. 2019; Di Fulvio et al. 2019; Rossi et al. 2018).

The UNEP-SETAC Life Cycle Initiative provides a global forum to ensure a science-based consensus-building process in the field of LCA (UNEP-SETAC Life Cycle Initiative 2016). One of its roles is to deliver an authoritative opinion on the effectiveness of accounting tools and approaches based on multi-stakeholder partnerships (e.g., governments, businesses, and scientific and civil society organizations), including recommendations on life cycle impact assessment methods. In 2016, the initiative concluded that the global average characterization factors ( $\mathrm{CFs}$ ) developed by Chaudhary et al. (2015) were suitable to assess potential impacts on biodiversity due to land use and land use change for hotspot analysis, only; that is, to identify relevant environmental aspects and their position in the life cycle for further investigation within the LCA study. Due to uncertainties associated with assessing biodiversity in the context of LCA, the initiative discouraged using these CFs for comparative assertions and product labeling, while encouraging further assessments to assess specific biodiversity risks for internal product comparisons.

The method proposed by Chaudhary et al. (2015) for quantifying land use impacts on biodiversity combines the countryside species-area relation (cSAR) models (Pereira and Daily 2006) and information on vulnerability. In contrast to the classical SAR model, the cSAR model accounts for the diversity of species responses to changes in habitat composition and the fact that species adapted to human-modified conditions also survive in the absence of their natural habitat.
Vulnerability is estimated based on the fraction of each species' geographic range (endemic richness) by ecoregion and the associated International Union for Conservation of Nature (IUCN) threat level of each species within that ecoregion. Chaudhary et al. (2015) proposed CFs for potential regional and global biodiversity loss using the cSAR model for both occupation (land use, LU) and transformation of land (land use change, LUC). Individual CFs are provided for:

- Six land use types ("intensive forestry,"1 "extensive forestry," “"annual crops," "permanent crops," "pasture," and "urban");

- Five taxonomic groups (mammals, birds, reptiles, amphibians, and vascular plants), along with all taxonomic groups but vascular plants (aggregated); and

- Different geographical resolutions (804 terrestrial ecoregions (Olson et al. 2001), country average, world average).

The UNEP-SETAC Life Cycle Initiative (UNEP-SETAC Life Cycle Initiative 2016) concluded that "[d]ue to the limitations on maturity of the method and land use types and intensity coverage, the recommendation [to use Chaudhary factors] is considered as interim until sufficient case studies are undertaken to test the robustness and ability of the model to identify potential biodiversity impacts."

Thus, as a means of addressing the UNEP-SETAC claim above, we developed a forest product case study (using corrugated boxes) to investigate the effectiveness of using global and ecoregion-based average CFs to identify life cycle hotspots and related improvement opportunities compared to using a land competition indicator. While there are existing LCAs on corrugated boxes, very little attention has been given to assessing potential inclusion of biodiversity aspects in these LCAs.

\section{Methods}

\subsection{Goal of LCA case study}

The primary objective of this case study was to apply the CFs for "Potential Species Loss" from Chaudhary et al. (2015) for hotspot analysis, and to identify potential improvement opportunities in the life cycle of corrugated boxes produced in the US.

\footnotetext{
${ }^{1}$ Forests with extractive use, with either even-aged stands and clear-cut patches, or less than three naturally occurring species at planting/seeding (Koellner et al. 2013).

${ }^{2}$ Forests with extractive use and associated disturbance like hunting, and selective logging, where timber extraction is followed by re-growth including at least three naturally occurring tree species (Koellner et al. 2013).
} 


\subsection{Product studied and functional unit}

The studied product was an average corrugated box manufactured in the US in 2014 (referred to as "US-average"). Corrugated boxes are made of corrugated board which is the structure formed by bonding one or more sheets of fluted, corrugating medium to one or more flat facings of linerboard. Together, fluted corrugating medium and linerboard are referred to as "containerboard." The functional unit was defined as:

"The domestic use of $1 \mathrm{~kg}$ of an average corrugated product produced in the US in 2014."

\subsection{System boundaries}

The LCA was undertaken using cradle-to-grave system boundaries, i.e., from raw material extraction (including the harvest of wood fiber) to the final disposal. More specifically, the following life cycle stages were considered:

1. Fiber procurement: This life cycle stage included forest operations, transportation of wood to chipping, off-site chipping and off-site production of market pulp, and transportation of chips or pulp to pulp and paper mills.

2. Pulp and papermaking: This stage included debarking and on-site production of chips, production of on-site produced pulp, papermaking operations (to produce containerboard), conversion into rolls, and supporting activities (on-site steam and power production, on-site chemical production, effluent treatment, on-site waste management, etc.).

3. Converting: The converting life cycle stage covered activities involved in converting containerboard into corrugated packaging (e.g., a box).

4. Use: For the use stage, only transportation to the user was considered.

5. End-of-life: This stage included the end-of-life management of the packaging product (i.e., landfilling and burning with energy recovery).

\subsection{Data collection and assumptions}

\subsubsection{Main data sources}

The study was based on site-specific (foreground) data from 42 containerboard mills representing $70 \%$ of US containerboard production and 166 converting facilities. This represented $23 \%$ of US overall corrugated products production volume for 2014. Background data were obtained from various data sources: the US Life Cycle Inventory Database (NREL 2012), the GaBi Database (thinkstep AG 2012), and the ecoinvent database (Wernet et al. 2016). The details of the inventory, with the exception of data pertaining to land occupation, have been published elsewhere (NCASI 2017).

\subsubsection{Occupation profile}

Quantity and type of fiber sourced by each of the 42 mills included in the study were obtained from the mills themselves. Occupation profiles, in $\mathrm{m}^{2}$ year, were calculated using typical yields and rotation lengths based on the literature (Table 1). Management intensities were derived from the USLCI Database (NREL 2012). Mass allocation was applied to wood fiber, meaning that logs and chips from the same species group had the same occupation profile.

Based on various data sources (NREL 2012; US Department of Transportation and US Department of Commerce 2015), we assumed that mills sourced wood fiber within a $150-\mathrm{km}$ radius. All forest ecoregions in a $150-\mathrm{km}$ radius of each mill were then identified. We estimated the area (hectares) of forest land held by US institutional owners in each ecoregion to confirm whether a specific ecoregion was likely to be a source of wood for paper production. To accomplish this, we used a geographic information system (GIS) layer depicting ecoregion boundaries (Olson et al. 2001) in combination with a confidential GIS layer that depicts boundaries of forest land held by institutional owners (NCASI, unpublished data). Total wood fiber supply was assumed to be equally supplied by each ecoregion within the $150-\mathrm{km}$ radius of the mill (Table 2), provided the ecoregion was identified as a likely source of wood for paper production.

\subsubsection{Impact assessment}

Life cycle assessment usually covers a wide variety of environmental aspects, for instance, global warming, acidification, and human health impacts. In this study, only one impact category was analyzed: biodiversity impacts associated with land use. In doing so, we applied the UNEP-SETAC Life Cycle Initiative recommendation to use the average, global, ecoregion-specific CFs from Chaudhary et al. (2015). While the regional CFs from Chaudhary et al. (2015) "give an estimate of regional species loss per unit of land use" per taxonomic group based on cSAR, the global CFs consider how the loss of species found in an ecoregion will translate into global species loss (extinction) by applying a vulnerability score to each of the species that considers the contribution of an ecoregion to the global biodiversity for the species and the threat level to that species according to the IUCN.

To "avoid misinterpretation," the UNEP-SETAC Life Cycle Initiative recommended labeling the results from applying these CFs as "Potential Species Loss from Land Use." For simplicity, in this paper, we dropped the "from land use" phrase, although the analysis was limited to land use and no other contributors to the potential change in biodiversity. 
Table 1 Assumed management intensities for fiber used by containerboard mills in 2014

\begin{tabular}{|c|c|c|c|c|}
\hline \multirow[t]{2}{*}{ Fiber type } & \multicolumn{3}{|c|}{$\begin{array}{l}\text { Management intensity } \\
\text { profile }\end{array}$} & \multirow[t]{2}{*}{ Sources/comment } \\
\hline & $\begin{array}{l}\text { Low } \\
(\%)\end{array}$ & $\begin{array}{l}\text { Medium } \\
(\%)\end{array}$ & $\begin{array}{l}\text { High } \\
(\%)\end{array}$ & \\
\hline $\begin{array}{l}\text { Logs, northern } \\
\text { hardwood } \\
\text { (LNH) } \\
\text { Chips, northern } \\
\text { hardwood } \\
\text { (CNH) }\end{array}$ & 59 & 25 & 16 & $\begin{array}{l}\text { Management intensities were derived from US LCI } \\
\text { database (pulpwood, hardwood, average, at forest road, } \\
\text { NE-NC), occupation profile from CORRIM (Johnson } \\
\text { et al. 2004) }\end{array}$ \\
\hline $\begin{array}{l}\text { Logs, southern } \\
\text { hardwood } \\
\text { (LSH) } \\
\text { Chips, southern } \\
\text { hardwood } \\
\text { (CSH) }\end{array}$ & 0 & 100 & 0 & $\begin{array}{l}\text { No data were available from US LCI and CORRIM for } \\
\text { southern hardwood logs. Hence, medium management } \\
\text { intensity was assumed. To obtain the occupation profile, } \\
\text { average yield value from and a rotation age of } 50 \text { years } \\
\text { was assumed based on data from FIA (Miles 2015) }\end{array}$ \\
\hline $\begin{array}{l}\text { Logs, southern } \\
\text { softwood } \\
\text { (LSS) } \\
\text { Chips, southern } \\
\text { softwood } \\
\text { (CSS) }\end{array}$ & 37 & 58 & 5 & $\begin{array}{l}\text { Management intensities were derived from US LCI } \\
\text { database (softwood logs with bark, harvested at average } \\
\text { intensity site, at mill, US SE), occupation profile from } \\
\text { CORRIM (Johnson et al. 2004) }\end{array}$ \\
\hline $\begin{array}{l}\text { Logs, northern } \\
\text { softwood } \\
\text { (LNS) } \\
\text { Chips, northern } \\
\text { softwood } \\
\text { (CNS) }\end{array}$ & 45 & 36 & 19 & $\begin{array}{l}\text { Management intensities were derived from US LCI } \\
\text { database (pulpwood, softwood, average, at forest road, } \\
\text { NE-NC), occupation profile from CORRIM (Oneil et al. } \\
\text { 2010) }\end{array}$ \\
\hline
\end{tabular}

Chaudhary et al. (2015) proposed sets of CFs for five taxonomic groups (mammals, birds, reptiles, amphibians, and vascular plants) and one set of CFs that aggregates all groups but vascular plants, all of which were applied in this study. Indicator results $\left(\mathrm{IR}_{\mathrm{i}}, i=1\right.$ : mammals, 2 : birds, 3 : reptiles, 4 : amphibians, 5: vascular plants, and 6: taxa-aggregated) for each of the five taxonomic groups as well as for the all taxaaggregated were calculated using Eq. 1. In Eq. 1, Occ $\mathrm{j}_{\mathrm{j}}$ is the total quantity of land occupied (in $\mathrm{m}^{2}$ year) for a land use type $j$ and $\mathrm{CF}_{\mathrm{i}, \mathrm{j}}$ is the characterization factor for taxonomic group $i$ and land use type $j$ (in global species-eq $/ \mathrm{m}^{2}$ year or potentially disappeared fraction $(\mathrm{PDF}) / \mathrm{m}^{2}$ year).

$I R_{i}=\sum_{j} O c c_{j} \times C F_{i, j}$

To be consistent with how data were collected for the various fiber sources (Table 1), we distinguished between "low," "medium," and "high" forest management intensities. More specifically, "low" management intensity was assigned to the CFs described by Chaudhary et al. (2015) for "Forest, extensive", while "high" management intensity was assigned to the "Forest, intensive" classification, and finally, "medium" management intensity was assigned to the average CFs of "Forest, extensive" and "Forest, intensive."
In addition, we applied a land competition indicator that simply represented the total surface of land occupied over a given period of time (in $\mathrm{m}^{2}$ year), often used in the past as a proxy for biodiversity impacts in LCA. This was done as a means to investigate the potential benefits and risks of using more complex indicators such as those presented by Chaudhary et al. (2015). Indicator results for that indicator were derived using Eq. 2.

$I R_{\text {Land }}$ Competition $=\sum_{j} O c c_{j}$

\subsection{Interpretation of the results}

To provide a more detailed interpretation of our results, we undertook a series of specific analyses:

1. Contribution/sensitivity analysis: We identified the life cycle stages, processes, and ecoregions contributing the most to the results and the taxonomic groups that were most affected, and then identified opportunities for improvement.

2. Scenarios analysis: We assessed the effect of making changes to the system in response to identified opportunities. 
Table 2 Estimated average wood fiber mix by ecoregion for USaverage corrugated boxes

\begin{tabular}{|c|c|c|}
\hline \multicolumn{2}{|c|}{ Ecoregion } & \multirow[t]{2}{*}{$\%$ of total fiber } \\
\hline No. & Name & \\
\hline \multicolumn{3}{|c|}{ Eastern US } \\
\hline NA0402 & Appalachian mixed mesophytic forests & 7.5 \\
\hline NA0403 & Appalachian-Blue Ridge forests & 5.7 \\
\hline NA0409 & Mississippi lowland forests & 8.8 \\
\hline NA0413 & Southeastern mixed forests & 20.3 \\
\hline NA0513 & Florida sand pine scrub & 1.5 \\
\hline NA0517 & Middle Atlantic coastal forests & 8.9 \\
\hline NA0523 & Piney Woods forests & 12.3 \\
\hline NA0529 & Southeastern conifer forests & 15.4 \\
\hline \multicolumn{3}{|c|}{ Central US } \\
\hline NA0405 & East Central Texas forests & 1.9 \\
\hline NA0412 & Ozark Mountain forests & 2.3 \\
\hline NA0414 & Southern Great Lakes forests & 1.2 \\
\hline NA0415 & Upper Midwest forest-savanna transition & 1.4 \\
\hline NA0416 & Western Great Lakes forests & 1.7 \\
\hline \multicolumn{3}{|c|}{ Western US } \\
\hline NA0417 & Willamette Valley forests & 1.6 \\
\hline NA0506 & British Columbia mainland coastal forests & 0.2 \\
\hline NA0507 & Cascade Mountains leeward forests & 0.2 \\
\hline NA0508 & Central and Southern Cascades forests & 1.6 \\
\hline NA0510 & Central Pacific coastal forests & 1.6 \\
\hline NA0512 & Eastern Cascades forests & 1.0 \\
\hline NA0516 & Klamath-Siskiyou & 0.6 \\
\hline NA0524 & Puget lowland forests & 0.6 \\
\hline
\end{tabular}

3. Uncertainty analysis: We tested robustness of the results to variability in proposed CFs.

\subsubsection{Contribution analyses}

Three types of contribution analyses were applied. First, it was determined how each life cycle stage (fiber procurement, pulp and papermaking, converting, use and end-of-life) contributed to the total score for each of the indicators proposed by Chaudhary et al. (2015). Second, to gain a greater understanding of which taxonomic group contributed the most to the taxa-aggregated indicator, we compared results for each specific taxonomic group. Third, expecting that fiber procurement would be an important contributor to each of these, the analysis was then broken down into the various ecoregions from which fiber was sourced for the product. For each ecoregion and each indicator, we estimated the ratio of the "Potential Species Loss" indicator result to the "Contribution to the Fiber Basket" (i.e., a sensitivity ratio (SR), see Eq. 3) to determine how sensitive each of the indicators was in each ecoregion. In this analysis, an SR of 1 indicated that contribution of fiber procurement in a given ecoregion was contributing to each of the "Potential Species Loss" indicators (one indicator for each taxonomic group and the taxa-aggregated indicator) in proportion to its contribution to the total fiber mix. An SR > 1 indicated that fiber procurement in a given ecoregion was particularly sensitive to the studied indicator, while a ratio $<1$ indicated a relatively low sensitivity of fiber procurement to the studied indicator in that ecoregion.

$S R_{i, k}=\frac{I R_{i, k}}{F_{k}}$

Where $k$ is a given ecoregion; $\mathrm{IR}_{\mathrm{i}, \mathrm{k}}$, the contribution of ecoregion $k$ to the indicator score for taxonomic group $i$; and $F_{\mathrm{k}}$, the fraction of fiber that comes from ecoregion $k$.

\subsubsection{Scenario analysis}

In addition to the base case scenario described by the modeling assumptions presented previously, several additional scenarios were investigated to assess improvement opportunities identified through the contribution analyses, and to evaluate the implications of some of the choices made in developing CFs (Table 3). The parameters that were identified as representing opportunities for improvement included the quantity of fiber consumed, the ecoregions supplying wood fiber to the paper mills, and the management intensity. Plants and birds appeared to represent the taxonomic groups with the most tradeoffs with other groups, and hence, it was decided to illustrate the effect of changing fiber sourcing to ecoregions that would appear to favor these groups.

\subsubsection{Uncertainty analysis}

There are various sources of uncertainty when using LCA. These are especially apparent in the data and models used for characterizing associated impacts. To highlight the potential effect of uncertainty in impact assessment, we used a Monte Carlo Analysis (10,000 iterations) by applying the 95\% confidence intervals on the CFs provided by Chaudhary et al. (2015) as limits and assuming triangular distributions. Triangular distributions were selected because minimum, average, and maximum values were available, but no information was available on the actual shape of the distribution. Only uncertainties associated with CFs used by Chaudhary et al. (2015) were considered (i.e., uncertainty in the LCA data was not considered), as this aided in directly assessing the recommendations made by the UNEP-SETAC Life Cycle Initiative. 
Table 3 Scenarios analyzed in the case study and related nomenclature

\begin{tabular}{|c|c|c|c|c|}
\hline Scenario set & Fiber consumption & $\begin{array}{l}\text { Geographical } \\
\text { resolution }\end{array}$ & Ecoregions included in a given mill's fiber basket & Management intensity \\
\hline Base case & $\begin{array}{l}\text { Based on data } \\
\text { collected from the } \\
\text { containerboard mills } \\
\text { (F100) }\end{array}$ & $\begin{array}{l}\text { Ecoregion-specific } \\
\quad(\text { ER) }\end{array}$ & $\begin{array}{l}\text { All wood supplying ecoregions located within a } \\
150-\mathrm{km} \text { radius of a given mill (ALL) }\end{array}$ & $\begin{array}{l}\text { Based on data collected from the } \\
\text { containerboard mills and the } \\
\text { US LCI database (AVG) }\end{array}$ \\
\hline \multirow{6}{*}{$\begin{array}{l}\text { Analysis of } \\
\text { improvement } \\
\text { opportunities }\end{array}$} & $\begin{array}{l}10 \% \text { reduction in fiber } \\
\text { use (F90) }\end{array}$ & Same as base case & & \\
\hline & Same as base case & & $\begin{array}{l}\text { Move a given mill fiber sourcing to ecoregion } \\
\text { with less sensitivity to the plant indicator } \\
\text { (plant) within the same fiber basin }\end{array}$ & Same as base case \\
\hline & Same as base case & & $\begin{array}{l}\text { Move a given mill fiber sourcing to ecoregion } \\
\text { with less sensitivity to the bird indicator (bird) } \\
\text { within the same fiber basin }\end{array}$ & Same as base case \\
\hline & Same as base case & & $\begin{array}{l}\text { Move a given mill fiber sourcing to ecoregion } \\
\text { with less sensitivity to the taxa-aggregated in- } \\
\text { dicator (TA) within the same fiber basin }\end{array}$ & Same as base case \\
\hline & Same as base case & & & $\begin{array}{l}\text { Assume all fiber comes from } \\
\text { extensive management } \\
\text { intensity (EXT) }\end{array}$ \\
\hline & Same as base case & & & $\begin{array}{l}\text { Assume all fiber comes from } \\
\text { intensive management } \\
\text { intensity (INT) }\end{array}$ \\
\hline $\begin{array}{l}\text { Evaluation of } \\
\text { choices made in } \\
\text { developing the } \\
\text { CFs }\end{array}$ & Same as base case & & $\begin{array}{l}\text { Move fiber sourcing in ecoregion described as } \\
\text { having the least habitat loss* }(\mathrm{HL}) \text { within the } \\
150-\mathrm{km} \text { radius }\end{array}$ & Same as base case \\
\hline
\end{tabular}

*The purpose of this analysis was to test possible unintended consequences of choices made in establishing the characterization factors. In the absence of specific information, data from The Atlas of Global Conservation was used (Hoekstra et al. 2010)

\section{Results and interpretation}

\subsection{Contribution analysis}

\subsubsection{Life cycle stages}

Fiber procurement showed to be the main contributor to the total score for all "Potential Species Loss" indicators proposed by Chaudhary et al. (2015). The fiber procurement life cycle stage contributed more than $90 \%$ of the indicator scores for mammals, amphibians, and reptiles; more than $80 \%$ of the value for birds; and approximately $80 \%$ for plants (Table 4 ). More specifically, within the fiber procurement life cycle stage, forest management for procuring the wood used in containerboard production contributed to at least $94 \%$ of the indicator scores, with the remainder coming from other background processes (e.g., transportation, fuel production, etc.). Background processes contributed the least to the land competition indicator score (1\%) and the most to the "Potential Species Loss"- vascular plants indicator score (6\%).

The results for the "Potential Species Loss"- taxa-aggregated indicator were similar to the results for the land competition indicator, suggesting that, in terms of hotspot identification, the surface occupied seems to be the main driver for the taxa-aggregated indicator, and the taxa-aggregated indicator provided little additional information compared to the land competition indicator, despite data collection efforts to regionalize the fiber supply.

\subsubsection{Taxonomic groups}

The application of the CFs from Chaudhary et al. (2015) indicated that the life cycle of corrugated boxes (and more specifically fiber procurement and forest management) potentially had the greatest effect on plants versus other taxonomic groups (Fig. 1), information that could not be obtained using the land competition indicator. The smallest effect was observed for mammals and reptiles. On the one hand, this result is generally consistent with what we would expect, in that forest management is more likely to influence species that are less mobile, such as plants. Species more adapted to disturbance may be more capable of movement/dispersal. Also, in more productive forests, such as those considered in this study, higher-level taxonomic groups may produce a lower magnitude response to forest management than the plant community which is directly affected by forest management (Kroll et al. 2017; 
Root et al. 2017). However, a meta-analysis of 96 studies synthesizing primary field research on response of understory plant diversity to timber harvesting in temperate forests in North America (forests from which most of the wood in the case study sourced) found little effect on understory plant species richness from managing forests for timber (Duguid and Ashton 2013). This indicates that, while the results obtained by applying the approach by Chaudhary et al. (2015) might provide information on which taxonomic groups are more at risk of being affected by forest management, site-specific assessments are still needed to understand its actual effect on species on a more local scale.

\subsubsection{Contribution and sensitivity of the different ecoregions to the fiber procurement results}

In the five ecoregions with the greatest contribution to the total fiber basket on a mass basis, fiber procurement was also an important contributor to at least some of the "Potential Species Loss" indicator scores (Table 5). For example, more than $20 \%$ of total fiber was derived from the Southeastern mixed forests ecoregion (NA0413), and fiber procurement in that region was responsible for $18.6 \%$ of the indicator score for birds.

Another interesting finding was that the contribution of some ecoregions to the indicator scores for some specific taxonomic groups was important despite low contribution to of these ecoregions to the fiber basket as further emphasized by the high ratios of "Potential Species Loss" to "Contribution to fiber basket" or SR. More specifically, we calculated SRs of:

- 11.9, 5.6, and 4.05, respectively for mammals in the Willamette Valley forests (NA0417), the Central Pacific coastal forests (NA0510), and the Central and Southern Cascades forests (NA0508);
- 4.9 for reptiles in the Florida sand pine (Pinus clausa) scrub (NA0513); and

- 4.3 for amphibians in the Appalachian-Blue Ridge forests (NA0403).

In the Willamette Valley, an area characterized by high conversion to agriculture and urbanization, the perceived extreme sensitivity of forest management to mammals is likely explained by the landscape context in this region. Indeed, the observed effects of forest management on vertebrate diversity have been shown to be more pronounced in forests embedded in agricultural or anthropogenic landscapes (Demarais et al. 2017). While this is not necessarily true for NA0417 and NA0510, other factors than forest management, such as historic trapping and hunting (Loehle and Eschenbach 2012; Vellend 2017), can further explain the lower number of species in these regions.

Research has shown that effects of forest management on reptiles and amphibians are region- and species-specific, with individual taxonomic groups responding positively, negatively, or not at all in the short-term, with very little information on long-term effects (Guzy et al. 2019). With regard to reptiles in the Florida sand pine scrub, research has indicated that forest management was more likely to affect reptile species composition than richness (Greenberg et al. 1994), again suggesting that other factors than those reflected in the approach from Chaudhary et al. (2015) might be occurring. Amphibians are likely to be sensitive to forest management, at least in the southern part of the Appalachians, and in the short term (Russell et al. 2004).

Figure 2 presents box and whisker plots of the sensitivity ratios (SR) grouped by regions. These plots present the minimum, first quartile, median, third quartile, and maximum values of SR in a given region. Several observations can be made concerning the variability of SRs that exists across the taxonomic groups and regions:
Table 4 Contribution of the life cycle stages to the different indicator score (F100-ER-AVG)

\begin{tabular}{|c|c|c|c|}
\hline Indicator & Fiber procurement (\%) & $\begin{array}{l}\text { Containerboard } \\
\text { production }(\%)\end{array}$ & Converting $(\%)$ \\
\hline "Potential Species Loss" - taxa-aggregated & 90.6 & 9.2 & 0.3 \\
\hline "Potential Species Loss"-mammals & 95.9 & 3.9 & 0.2 \\
\hline "Potential Species Loss"—-birds & 86.9 & 12.8 & 0.3 \\
\hline "Potential Species Loss"- - vascular plants & 80.3 & 19.0 & 0.6 \\
\hline "Potential Species Loss"—amphibians & 93.9 & 6.0 & 0.1 \\
\hline "Potential Species Loss"—reptiles & 92.0 & 7.8 & 0.2 \\
\hline Land competition & 90.5 & 9.4 & 0.2 \\
\hline
\end{tabular}

NOTE: The use and end-of-life stages were omitted from this table because of their marginal contribution to the different indicator scores 
Fig. 1 Contribution of each taxonomic group to "Potential Species Loss"- taxa-aggregated indicator results

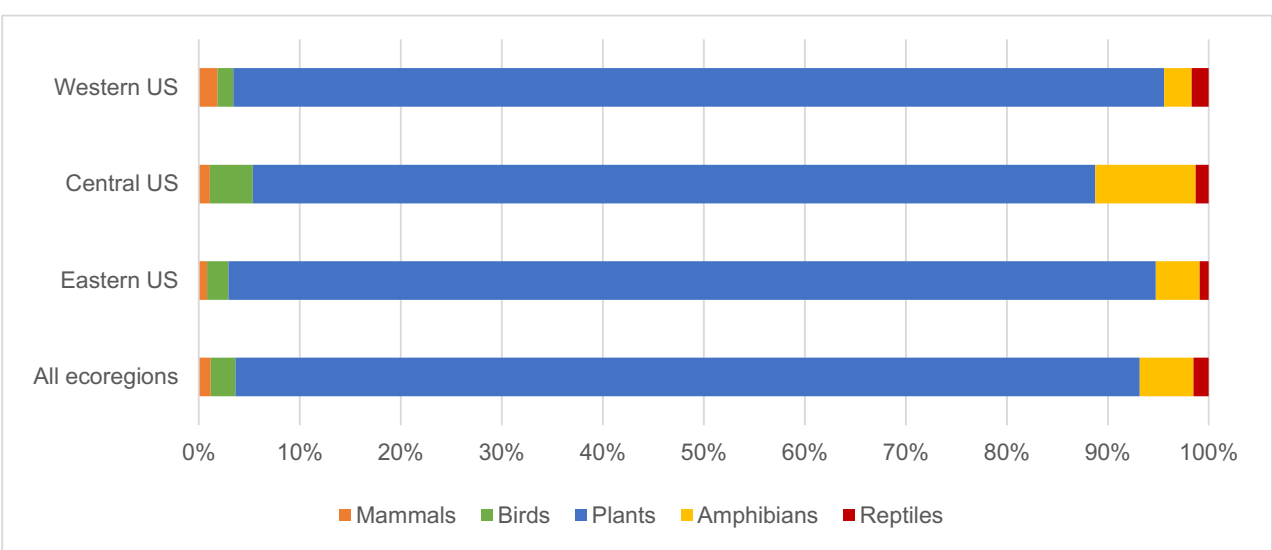

- Across all ecoregions included in this study, birds showed less sensitivity to forest management than other species;

- The highest and most variable average sensitivity observed was in the Western ecoregions especially for mammals; and

- Central and eastern ecoregions showed less sensitivity to species across taxonomic groups and ecoregions.

Bird response to disturbance has been found to vary with ecosystem productivity and, in ecosystems with relatively high productivity, forest management often has a positive effect on species richness (Guzy et al. 2019; McWethy et al. 2010; Phillips et al. 2010; Verschuyl et al. 2008). A lower sensitivity of birds to forest management than other taxonomic groups can be attributed to their mobility.

Western ecoregions are uniquely heterogeneous due to a higher topographic complexity than other regions in our study, which may explain the greater variability observed for all taxonomic groups in these regions. The regional variability, coupled with the fact that the proposed CFs have considerable uncertainty and range from showing beneficial to a negative impact on biodiversity depending on local conditions (Chaudhary et al. 2015), indicates that using ecoregion-based factors is not sufficient to characterize the effect of forest management on "Potential Species Loss" and that greater spatial granularity would be needed.

Table 5 Contribution of fiber procurement in the five ecoregions contributing the most to each of the indicator scores

\begin{tabular}{|c|c|c|c|c|c|c|c|c|}
\hline \multicolumn{2}{|l|}{ Ecoregion } & \multirow{2}{*}{$\begin{array}{l}\% \text { of total fiber (mass } \\
\text { basis) }\end{array}$} & \multicolumn{6}{|c|}{ "Potential Species Loss" indicator } \\
\hline No. & Name & & $\begin{array}{l}\text { Taxa- } \\
\text { aggregated }(\%)\end{array}$ & $\begin{array}{l}\text { Mammals } \\
(\%)\end{array}$ & $\begin{array}{l}\text { Birds } \\
(\%)\end{array}$ & $\begin{array}{l}\text { Vascular plants } \\
(\%)\end{array}$ & $\begin{array}{l}\text { Amphibians } \\
(\%)\end{array}$ & $\begin{array}{l}\text { Reptiles } \\
(\%)\end{array}$ \\
\hline \multicolumn{9}{|l|}{ Eastern US } \\
\hline NA0402 & $\begin{array}{l}\text { Appalachian mixed } \\
\text { mesophytic forests }\end{array}$ & 7.5 & & & & & 9.1 & \\
\hline NA0403 & $\begin{array}{l}\text { Appalachian-Blue Ridge } \\
\text { forests }\end{array}$ & 5.7 & 10.3 & & & & 24.6 & \\
\hline NA0409* & Mississippi lowland forests & 8.8 & & & 10.1 & & & \\
\hline NA0413* & Southeastern mixed forests & 20.3 & 11.6 & 8.4 & 18.6 & 8.5 & 10.8 & 9.9 \\
\hline NA0513 & Florida sand pine scrub & 1.5 & & & & & & 7.3 \\
\hline NA0517* & Middle Atlantic coastal forests & 8.9 & 8.7 & 10.9 & 9.7 & 9.0 & 6.7 & 8.2 \\
\hline NA0523* & Piney Woods forests & 12.3 & 7.5 & & 7.7 & 10.0 & & 19.1 \\
\hline NA0529* & Southeastern conifer forests & 15.4 & 16.1 & 12.4 & 14.2 & 13.7 & 15.9 & 30.0 \\
\hline \multicolumn{9}{|c|}{ Western US } \\
\hline NA0417 & Willamette Valley forests & 1.6 & & 19.1 & & & & \\
\hline NA0510 & Central Pacific coastal forests & 1.6 & & 9.1 & & 4.5 & & \\
\hline
\end{tabular}

*Ecoregions with the most contribution to the overall fiber basket. Blank cell: Ecoregion is not one of the five contributing the most to the indicator. Italicized data indicate cases where fiber procurement in a given ecoregion contributes importantly to results despite relatively low or lower contribution from the fiber basket 


\subsubsection{Uncertainty analysis}

While fiber procurement was the main contributor to indicator scores for all simulations, its actual contribution varied considerably ( 73 to $108 \%$ ) due to uncertainty in the CFs; note that a contribution of $108 \%$ for fiber procurement would mean that at least one additional life cycle stage contributed negatively to the indicator score. According to Chaudhary et al. (2015), uncertainty in the CFs is mainly driven by applying data from broader spatial scales than to a specific ecoregion when developing these CFs (Chaudhary et al. 2015), which further illustrates the importance of site-specific analyses.

\subsection{Scenario analyses}

\subsubsection{Fiber consumption scenario}

Reducing fiber consumption by $10 \%$ resulted in a reduction of indicator scores by 8 to $10 \%$, indicating that the main driver for these scores remained the surface occupied (more fiber use equated to more surface area occupied). However, the results of individual Monte Carlo simulations were highly variable. We found that reducing fiber consumption by $10 \%$ resulted in -36 to $+9 \%$ changes in the "Potential Species Loss"- taxa-aggregated indicator score compared with the baseline scenario, where $95 \%$ of our results fell within the range of -21 and $+5 \%$. In $34 \%$ of the simulation runs, a decrease in fiber consumption by $10 \%$ led to an increase in the indicator value. According to Chaudhary et al. (2015), variability in CFs for each ecoregion is mainly explained by differences in local conditions. This indicates that in the absence of CFs being further spatially differentiated, it is difficult to analyze whether reducing fiber consumption will improve the indicator result.

\subsubsection{Ecoregion scenarios}

As discussed above, the application of the CFs from Chaudhary et al. (2015) yielded the following results: plants were shown to be especially affected by forest management, and forest management was shown to have a variable effect on different taxonomic groups within different ecoregions. We used these results to define and assess potential fiber sourcing improvement opportunities. Moving fiber sourcing to ecoregions with less sensitivity to the taxa-aggregated indicator led to the greatest average improvement on calculated indicator scores (see Fig. 3). Bird species were the least improved when managing for plants or to improve the taxaaggregated indicator. In contrast, moving fiber sourcing to ecoregions where birds were less sensitive to forest management seemed to have less of an effect on the other taxonomic groups, except for the negative effects on amphibians. This result may be explained by the fact that we moved a significant portion of fiber sourcing to NA0403, a region where amphibians were shown to be highly sensitive to forest management. We cannot conclude from these limited results that there will consistently be a tradeoff between birds and amphibians.

In a third ecoregion scenario, we tested the effect of moving, for each mill, fiber sourcing to the ecoregion within the $150-\mathrm{km}$ sourcing area that was described by Hoekstra et al. (2010) as having the least current "habitat loss" (F100-ERHL-AVG). The results in Fig. 4 show that moving fiber between ecoregions generally improved indicator scores. In other words, the CFs proposed by Chaudhary et al. (2015) seem to encourage moving fiber procurement to "less altered" regions, at least per the Hoekstra et al. (2010) definition. This result can likely be explained as an artifact of using the cSAR in developing CFs, which would assume that, in places where little original forest remains, any alteration of the remaining forest could result in more species being lost per unit habitat
Fig. 2 Variability of sensitivity ratios across different regions and taxonomic groups

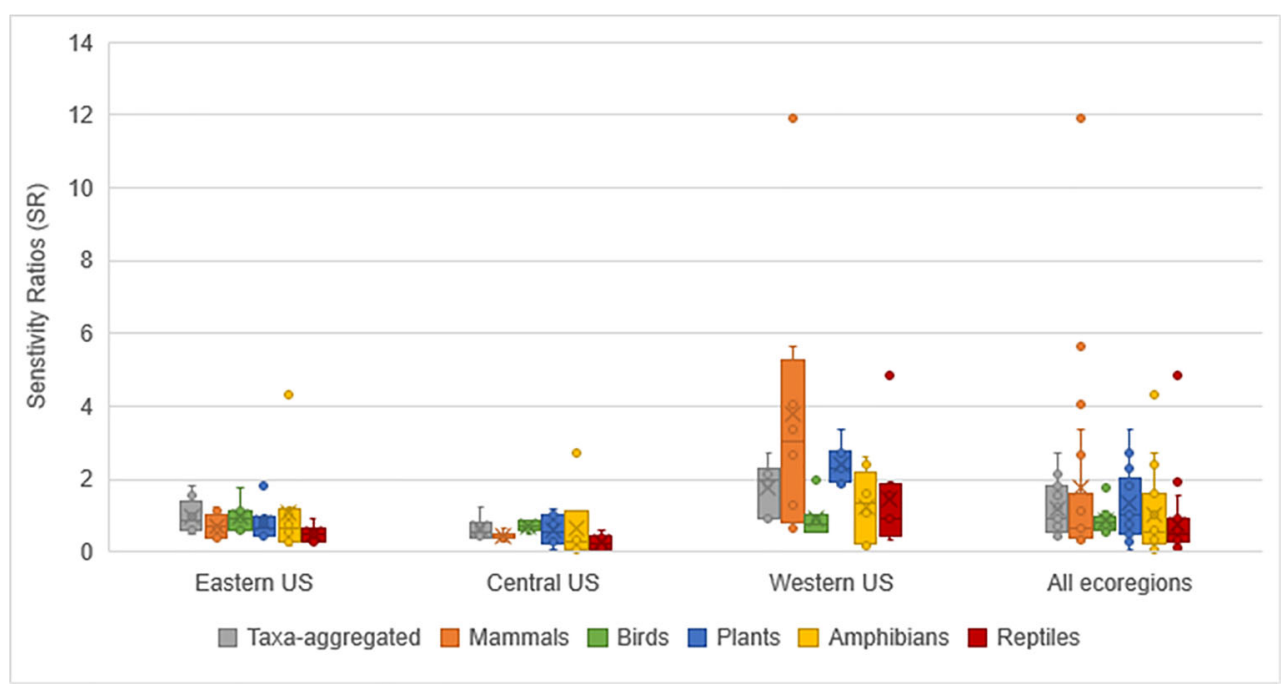


loss. The limitations of using SAR-based model in evaluating the opportunity for improvement in forest products LCAs are further discussed below.

\subsubsection{Management intensity scenarios}

Altering intensity of management from an US-average level (as computed in the US LCI database for the various regions) to exclusively extensive (F100-ER-ALL-EXT) or exclusively intensive (F100-ER-ALL-INT) management had several outcomes (Fig. 5).

The "Potential Species Loss"-vascular plants indicator responded similarly to the land competition indicator (i.e., more intensive management led to a reduction in the potential impact, Fig. 5). More specifically, the lower intensity forest management strategy (extensive) used $+124 \%$ more surface area than the higher management intensity (intensive), which resulted in $a+120 \%$ greater potential impact on the plant indicator score. Although this appears to suggest that the plant indicator was less sensitive to the effect of management intensity on plant species than to the amount of land occupied, the individual CFs showed that this is not always the case but rather that, with regard to plants, the sensitivity to management intensity of the indicator score was ecoregion-specific.

The "Potential Species Loss"-mammals indicator score also responded negatively to switching management intensity from average to exclusively extensive, and more profoundly than that of plants (Fig. 5). Contrary to plants, however, most CFs for mammals were significantly greater for extensive forest management than for intensive forest management for the ecoregions considered in this study. This indicates not only that the surface occupied was a greater driver of the indicator score for mammals than the intensity of management but that, when controlling for total area of management, extensive forest management showed more effect on the mammal indicator score than intensive forest management. This result is counterintuitive.

Birds, amphibians, and, to a lesser degree, reptiles, all had lower observed "Potential Species Loss" under extensive forest management than under average or intensive forest management, indicating that these taxonomic groups were more affected by management intensity than by the surface occupied by forest management activities. Amphibians and reptiles are less mobile and more affected by environmental conditions than birds and hence likely more affected by forest management intensity. However, with regard to birds, we would expect that a reduction in species specialized for late-seral forest types would be at least compensated for by species specialized for early seral forest types (Verschuyl et al. 2008).

There is limited information currently in the literature on responses of various taxonomic groups to forest management intensification (see Demarais et al. 2017). In higher productivity regions with more resilient higher-level taxonomic groups (e.g., mammals) and with species less tied to specific locations on the landscape in question, intensification (land sparing) might be an appropriate management approach to improve species diversity (McWethy et al. 2010; Verschuyl et al. 2008). In less productive regions, the reverse may be true.

\section{Discussion}

\subsection{Limitations of SAR-based approaches}

Results showed that when applying the factors proposed by Chaudhary et al. (2015), fiber procurement was the main contributor to the "Potential Species Loss" indicator scores for all taxonomic groups considered, although the contribution varied among taxonomic groups (Table 4). Results for the taxa-
Fig. 3 Effect of moving fiber sourcing to ecoregions with less sensitivity to studied indicators

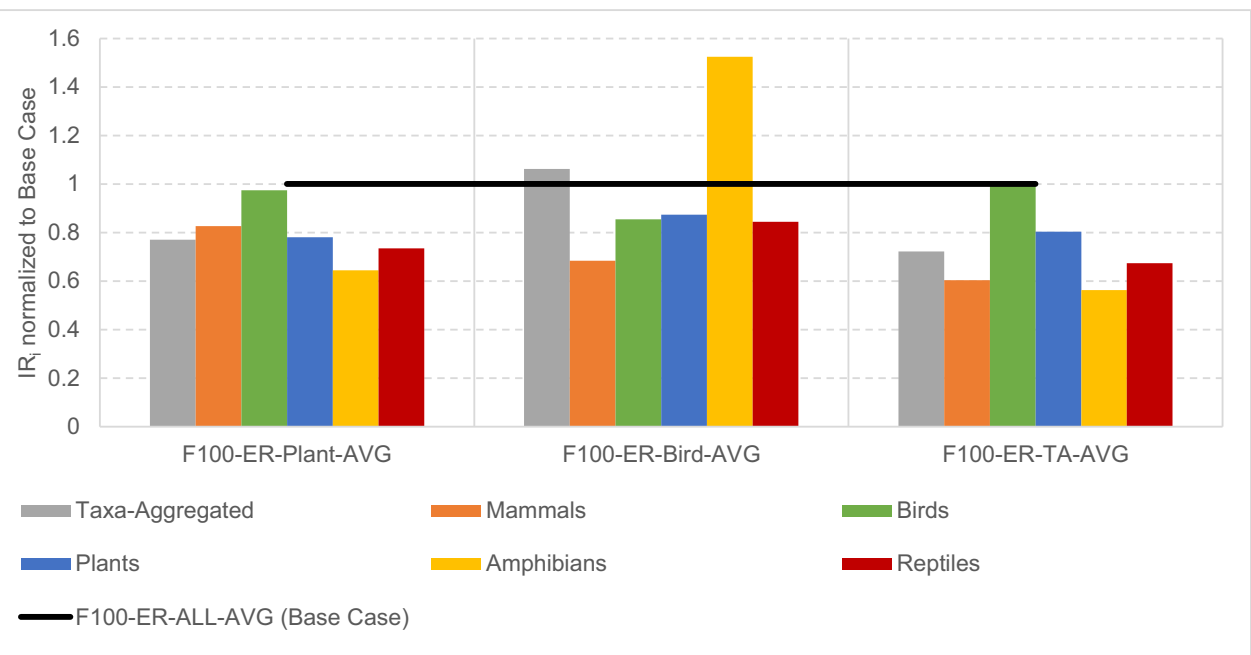


Fig. 4 Effect of moving fiber sourcing to ecoregions described as having less "Habitat Loss"

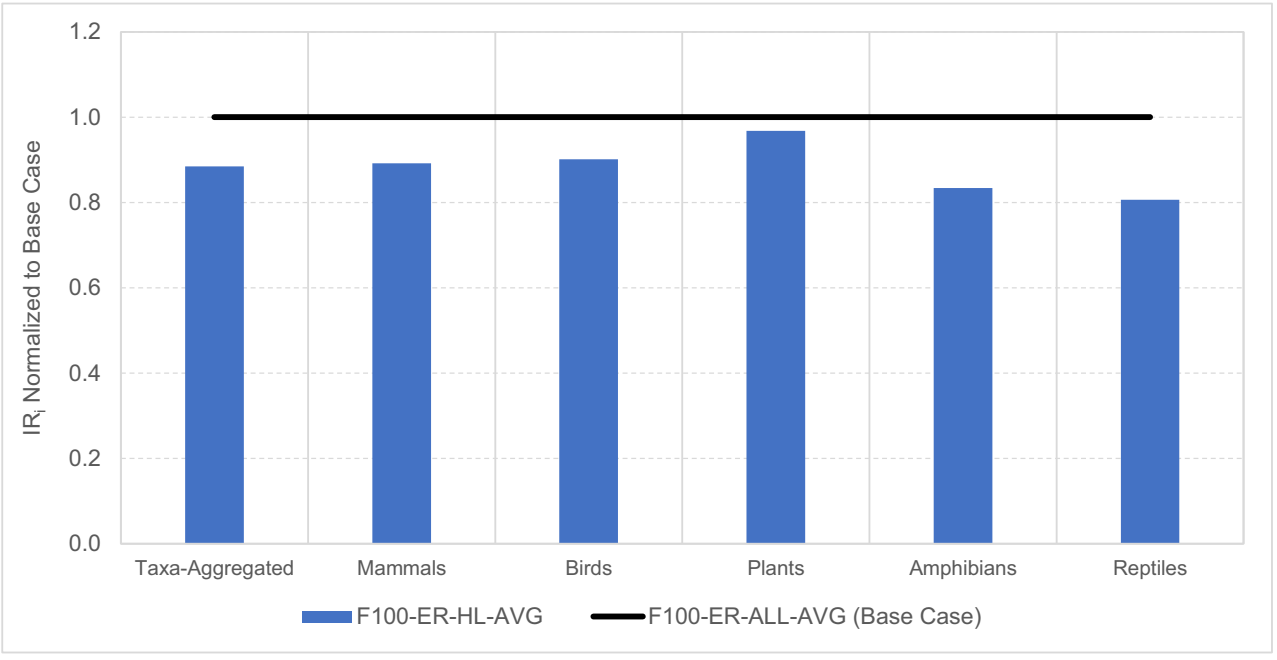

aggregated indicator were similar to those for the land competition indicator in terms of determining the contribution of life cycle stages, at least directionally. This finding is not surprising given that forest management is by far the greatest user of land in the life cycle of corrugated boxes (and likely any other forest product) and that the surface occupied is the main driver behind the cSAR approach used by Chaudhary et al. (2015) in developing CFs. Approaches for which the surface occupied is the main driver assume that the larger an area of land is, the greater variety of species it will contain, and hence the more species will be necessarily affected by land use. The SAR model, in particular, as used by Chaudhary et al. (2015), appears to extrapolate from either stand-level post-harvest (i.e., short-term) effects compared to natural older forests and/or to fail to consider the landscape scale within which forestry operates. Also, the CFs were obtained by comparing number of species in a given ecoregion for natural conditions versus the current land use type, and then attributing the difference in species to the current land use type with little consideration of the landscape context or of the temporal dynamics of biodiversity; this assumes that a constant "biodiversity score" can be assigned to occupied land (de Baan et al. 2013). Using this approach, there is a significant risk of overestimating the effect of forest management on species diversity.

There are other important limitations from applying SARbased indicators such as the CFs proposed by Chaudhary et al. (2015) to forest management that should be discussed. The SAR is a sample-based relationship rather than one based on species ranges. One fundamental weakness in applying sample-based approaches to an arbitrary area (e.g., an ecoregion) is that the species found are rarely confined to that particular area. In the context of a county/district, for example, urban development would progressively move towards all species from that county being "lost," while in reality, fewto-none would actually become extinct because their geographic ranges encompass entire states and regions. Thus, what it means for a species to be "lost" when using the SAR to assess effects needs to be further clarified. Although less pronounced with a cSAR model than a classical SAR model,
Fig. 5 Effect of management intensities on observed "Potential Species Loss" indicator results

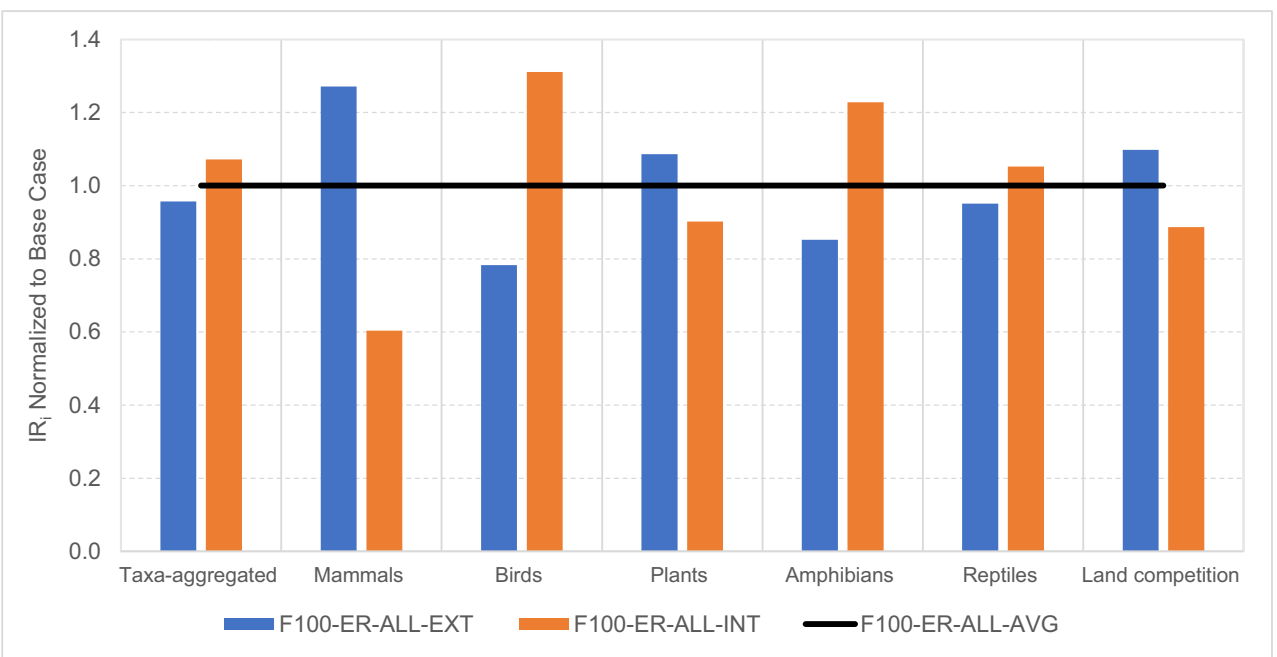


even a perfect application of the model would only describe pseudo-extinctions (losses from particular areas), not global extinctions. Most forests are subject to natural disturbances (e.g., fire, insect outbreaks, drought) that create a landscape consisting of a mix of age classes and successional stages, very much like a managed forest landscape that typically includes unmanaged parcels or reserves mixed in with managed stands. In fact, extensive research has shown that forest management in a landscape context that includes unmanaged parcels increases spatial complexity and thus, biodiversity (e.g., Gustafson et al. 2007; Loehle et al. 2005a, b; Mitchell et al. 2006, 2008). A small subset of all species appears to depend exclusively on old-growth forests (e.g., some lichens, northern spotted owl, some forest herbs), but these species appear to be lost mainly on managed stands while being conserved on unmanaged lands. Research showed that, in North America, well-established regulatory framework of federal and state laws, and non-regulatory forest certification standards benefit a variety of species that would be sensitive to changes in forest structure (e.g., Warrington et al. 2017) and forestry can provide early seral conditions that are not provided without forest disturbance (Swanson et al. 2014). This may benefit birds associated with young forests, for example, which may not occur or may be far less abundant in older forests. This is not reflected by using a single metric for birds. The net result of these landscape-scale effects is that forest management can increase habitat diversity at larger than stand scales (Swanson et al. 2014). Except for a few species that depend on older natural forests, most species likely persist in managed forests and are not at increased risk of being lost. In fact, almost no species have been documented to have gone extinct due to forest management in North America (Loehle and Eschenbach 2012).

\subsection{Limitations with spatial resolution and forest management intensity levels}

One important feature of the CFs from Chaudhary et al. (2015) compared to the land competition indicator is the ability to distinguish between taxonomic groups and ecoregions. Hence, using these CFs, we were able to determine which ecoregions were contributing the most to the results and assess the effects of moving fiber sourcing from one ecoregion to another. Using this approach, moving fiber sourcing away from ecoregions where vascular plants were the most sensitive to forest management was shown to be beneficial to indicator scores for all taxonomic groups. However, this finding should be taken with caution. Moving fiber sourcing from one ecoregion to another may not be feasible in practice. There may be physical/economic constraints or other environmental considerations. More importantly, we showed that the uncertainty in the ecoregion-based
CFs could have significant implications on the results. The actual local conditions associated with fiber sourcing in a given ecoregion can be far from the average conditions in that same ecoregion leading to the potential for counterproductive land management decisions. Also, while the reduction of fiber consumption showed a benefit for the taxa-aggregated indicator, the results of the uncertainty analysis showed that this result was very site-specific. Indeed, in several cases, reducing fiber consumption was detrimental to the indicator score, indicating the lack of usefulness of the CFs in the absence of greater spatial resolution.

Results indicated that the indicator scores derived from applying the recommended CFs for the different taxonomic groups responded differently to management intensity. Indicator scores for mammals and vascular plants responded better to higher management intensities (intensive), while indicator scores for the other taxonomic groups responded better under lower management intensities (extensive). However, the effect of management intensity on species diversity is not binary. For instance, a study on the effect of management intensity on vertebrate species in the US (Demarais et al. 2017) showed that responses to intensive forest management are species-specific and dependent on the seral stage. Interestingly, actual management practices are probably the most actionable lever by forest managers to have a positive effect on species richness. For instance, management practices such as thinning, retaining structure, and protecting riparian zones and sensitive ecological areas can have positive effects on most vertebrate taxa or mitigate effects of harvesting (Demarais et al. 2017; Parrish et al. 2017), again illustrating the weakness of indicator for which the surface occupied is the main driver. In the current proposed UNEP-SETAC framework, site-specific actions to improve biodiversity would not be reflected in LCA results. Therefore, CFs would need to be derived for more management practices than extensive and intensive. This was recognized by Chaudhary and Brooks (2018) that proposed new CFs for six different intensity forest management practices: three "managed forests" intensities and three "plantation forests" intensities. The testing of the new CFs by Chaudhary and Brooks (2018) showed that it was possible to differentiate the biodiversity effect caused under these categories of intensity, which certainly represent an improvement compared to what was recommended by the UNEP-SETAC in 2016. However, even with these new CFs, we expect that improvement from on-site practices would still be shown as marginal because CFs are defined by using an approach that involves comparing species to ideal natural conditions. Therefore, unless CFs were to be developed using other comparison points, their application would provide minimal incentive for improvement, given that a return to ideal natural conditions is pragmatically impossible. 


\subsection{Other general limitations}

Simplified approaches such as the CFs by Chaudhary et al. (2015) dismiss the many other drivers of biodiversity, such as habitat heterogeneity and climatic conditions (de Souza et al. 2015). Also, we obtained results suggesting that moving fiber sourcing to ecoregions that are currently "less altered" (at least according to Hoekstra et al. (2010)) will lead to an overall improvement of the indicator scores, a questionable result.

\section{Conclusions and recommendations}

We have shown that the application of the CFs from Chaudhary et al. (2015) provided some additional information compared to the land competition indicator. For instance, with regard to tradeoffs between ecoregions and taxonomic groups, but that the additional information was more at risk of producing counterproductive forest management decisions when applied to identify and evaluate potential opportunities for improvement. The strength of these CFs is most likely when applied to complex value chains with several land use types involved. The main difference in applying the UNEP-SETAC factors was the ability to distinguish among taxonomic groups and ecoregions. In addition, we discussed that the use of an "ideal natural conditions" baseline in developing these factors provides little incentive for making improvements. The limitations of the proposed CFs include, for instance, their low spatial resolution, the limited management intensities covered, and using the SAR. This finding is consistent with de Baan et al. (2013) who concluded that the "characterization factors $[. .$.$] can approximate land use impacts on biodiversity$ in LCA studies that are not [emphasis added] intended to support decision-making on land management practices directly."

Successful consideration of biodiversity response in the context of LCA, especially in the context of forest management, requires integration of other approaches such as sitespecific and/or territorial studies or analyses that should be considered as an essential, complementary tool to LCA, to mitigate against inaccurate conclusions about local management practices and their effects on the landscape (Teixeira et al. 2015). Potential improvements to the proposed method include further spatialization of $\mathrm{CFs}$, the definition of a range of forest management practices for which CFs would be developed, consideration of forest productivity, and definition CFs using a baseline that would encourage better practices even within a given current management regime.

Open Access This article is licensed under a Creative Commons Attribution 4.0 International License, which permits use, sharing, adaptation, distribution and reproduction in any medium or format, as long as you give appropriate credit to the original author(s) and the source, provide a link to the Creative Commons licence, and indicate if changes were made. The images or other third party material in this article are included in the article's Creative Commons licence, unless indicated otherwise in a credit line to the material. If material is not included in the article's Creative Commons licence and your intended use is not permitted by statutory regulation or exceeds the permitted use, you will need to obtain permission directly from the copyright holder. To view a copy of this licence, visit http://creativecommons.org/licenses/by/4.0/.

\section{References}

Chapin FS et al (2000) Consequences of changing biodiversity. Nature 405:234-242. https://doi.org/10.1038/35012241

Chaudhary A, Brooks TM (2018) Land use intensity-specific global characterization factors to assess product biodiversity footprints. Environ Sci Technol 52:5094-5104. https://doi.org/10.1021/acs.est.7b05570

Chaudhary A, Verones F, de Baan L, Hellweg S (2015) Quantifying land use impacts on biodiversity: combining species-area models and vulnerability indicators. Environ Sci Technol 49:9987-9995. https://doi.org/10.1021/acs.est.5b02507

Côté S, Bélanger L, Beauregard R, Thiffault É, Margni M (2019) A conceptual model for forest naturalness assessment and application in Quebec's. Boreal Forest Forests 10:325

de Baan L, Alkemade R, Koellner T (2013) Land use impacts on biodiversity in LCA: a global approach. Int J LCA 18:1216-1230. https:// doi.org/10.1007/s11367-012-0412-0

de Souza DM, Teixeira RFM, Ostermann OP (2015) Assessing biodiversity loss due to land use with Life Cycle Assessment: are we there yet? Glob Chang Biol 21:32-47. https://doi.org/10.1111/gcb.12709

Demarais S, Verschuyl JP, Roloff GJ, Miller DA, Wigley TB (2017) Tamm review: terrestrial vertebrate biodiversity and intensive forest management in the U.S. Forest Ecol Manag 385:308-330. https:// doi.org/10.1016/j.foreco.2016.10.006

Di Fulvio F, Forsell N, Korosuo A, Obersteiner M, Hellweg S (2019) Spatially explicit LCA analysis of biodiversity losses due to different bioenergy policies in the European Union. Sci Total Environ 651:1505-1516. https://doi.org/10.1016/j.scitotenv.2018.08.419

Duguid MC, Ashton MS (2013) A meta-analysis of the effect of forest management for timber on understory plant species diversity in temperate forests. Forest Ecol Manag 303:81-90. https://doi.org/10. 1016/j.foreco.2013.04.009

EEA (1995) Europe's environment: the Dobris assessment. Copenhagen, Denmark http://www.eea.europa.eu/publications/92-826-5409-5

Food and Agriculture Organization of the United Nations (FAO) (1976) A framework for land evaluation. vol FAO Soil Bulletin No. 32. Rome, Italy

Gaudreault C, Wigley TB, Margni M, Verschuyl J, Vice K, Titus B (2016) Addressing biodiversity impacts of land use in life cycle assessment of forest biomass harvesting. WIRes Energy Environ 5:670-683. https://doi.org/10.1002/wene.211

Greenberg CH, Neary DG, Harris LD (1994) Effect of high-intensity wildfire and silvicultural treatments on reptile communities in sand-pine scrub. Conserv Biol 8:1047-1057. https://doi.org/10. 1046/j.1523-1739.1994.08041047.x

Gustafson EJ, Lytle DE, Swaty R, Loehle C (2007) Simulating the cumulative effects of multiple forest management strategies on landscape measures of forest sustainability. Landsc Ecol 22:141-156. https://doi.org/10.1007/s10980-006-9017-y

Guzy JC, Halloran KM, Homyack JA, Thornton-Frost JE, Willson JD (2019) Differential responses of amphibian and reptile assemblages to size of riparian buffers within managed forests. Ecol Appl 29: e01995. https://doi.org/10.1002/eap.1995 
Hoekstra JM et al (2010) The atlas of global conservation: changes, challenges and opportunities to make a difference. University of California Press, Berkeley

Johnson LR, Lippke B, Marshall JD, Comnick J (2004) Module A: Forest Resources Pacific Northwest and Southeast In: CORRIM: Phase I Final Report $\mathrm{p} 72$

Koellner T et al (2013) Principles for life cycle inventories of land use on a global scale. Int J LCA 18:1203-1215. https://doi.org/10.1007/ s11367-012-0392-0

Kroll AJ, Verschuyl J, Giovanini J, Betts MG (2017) Assembly dynamics of a forest bird community depend on disturbance intensity and foraging guild. J Appl Ecol 54:784-793. https://doi.org/10.1111/ 1365-2664.12773

Loehle C, Eschenbach W (2012) Historical bird and terrestrial mammal extinction rates and causes. Divers Distrib 18:84-91. https://doi.org/ 10.1111/j.1472-4642.2011.00856.x

Loehle C et al (2005a) Managed forest landscape structure and avian species richness in the southeastern US. Forest Ecol Manag 214: 279-293. https://doi.org/10.1016/j.foreco.2005.04.018

Loehle C, Wigley TB, Shipman PA, Fox SF, Rutzmoser S, Thill RE, Melchiors MA (2005b) Herpetofaunal species richness responses to forest landscape structure in Arkansas. Forest Ecol Manag 209: 293-308. https://doi.org/10.1016/j.foreco.2005.02.007

McWethy D, Hansen A, Verschuyl J (2010) Bird response to disturbance varies with forest productivity in the northwestern United States. Landsc Ecol 25:533-549. https://doi.org/10.1007/s10980-0099437-6

Milà i Canals L, Bauer C, Depestele J, Dubreuil A, Freiermuth Knuchel R, Gaillard G, Michelsen O, Müller-Wenk R, Rydgren B (2007) Key elements in a framework for land use impact assessment in LCA. Int J LCA 12:2-4. https://doi.org/10.1065/lca2006.05.250

Miles PD (2015) Forest Inventory EVALIDator web-application Version 1.6.0.03. St. Paul, MN: US Department of Agriculture, Forest Service, Northern Research Station. https://apps.fs.usda.gov/ Evalidator/evalidator.jsp. Accessed December 11, 2017

Mitchell MS et al (2008) Projected long-term response of Southeastern birds to forest management. Forest Ecol Manag 256:1884-1896. https://doi.org/10.1016/j.foreco.2008.07.012

Mitchell MS et al (2006) Relationships between avian richness and landscape structure at multiple scales using multiple landscapes. Forest Ecol Manag 221:155-169. https://doi.org/10.1016/j.foreco.2005.09. 023

National Council for Air and Stream Improvement, Inc. (NCASI) (2017) 2014 Life Cycle Assessment of U.S. Average Corrugated Product. Corrugated Packaging Alliance (CPA), Cary, NC. http://www. corrugated.org/upload/NCASI\%202014\%20LCA_Final.pdf

National Renewable Energy Laboratory (NREL) (2012) USLCI Database. (accessed Version implemented in SimaPro Software, Updated September 2015)

Newbold T et al (2015) Global effects of land use on local terrestrial biodiversity. Nature 520:45-50. https://doi.org/10.1038/ nature 14324

Oldemann LR, Hakkeling RTA, Sombroek WG (1991) World map of the status of human-induced soil degradation. ISRIC, UNEP

Olson DM, Dinerstein E, Wikramanayake ED, Burgess ND, Powell GVN, Underwood EC, D'amico JA, Itoua I, Strand HE, Morrison JC, Loucks CJ, Allnutt TF, Ricketts TH, Kura Y, Lamoreux JF, Wettengel WW, Hedao P, Kassem KR (2001) Terrestrial ecoregions of the world: a new map of life on Earth. BioScience 51:933-938. https://doi.org/10.1641/0006-3568(2001)051[0933:teotwa]2.0.co;2

Oneil EE, Johnson LR, Lippke BR, McCarter JB, McDill ME, Roth PE, Finley JC (2010) Life-cycle impacts of inland northwest and northeast/north central forest resources. Wood Fiber Sci 42:29-51
Parrish MC, Demarais S, Wigley TB, Jones PD, Ezell AW, Riffell SK (2017) Breeding bird communities associated with land cover in intensively managed pine forests of the southeastern. US Forest Ecol Manag 406:112-124. https://doi.org/10.1016/j.foreco.2017. 09.063

Pereira HM, Daily GC (2006) Modeling biodiversity dynamics in countryside landscapes. Ecology 87:1877-1885. https://doi.org/10.1890/ 0012-9658(2006)87[1877:mbdicl]2.0.co;2

Phillips LB, Hansen AJ, Flather CH, Robison-Cox J (2010) Applying species - energy theory to conservation: a case study for North American birds. Ecol Appl 20:2007-2023

Pimentel D, Harvey C, Resosudarmo P, Sinclair K, Kurz D, McNair M, Crist S, Shpritz L, Fitton L, Saffouri R, Blair R (1995) Environmental and economic costs of soil erosion and conservation benefits. Science 267:1117-1123. https://doi.org/10.1126/science. 267.5201.1117

Root HT, Verschuyl J, Stokely T, Hammond P, Scherr MA, Betts MG (2017) Plant diversity enhances moth diversity in an intensive forest management experiment. Ecol Appl 27:134-142. https://doi.org/10. 1002/eap. 1426

Rossi V et al (2018) Capturing the potential biodiversity effects of forestry practices in life cycle assessment. Int J LCA 23:1192-1200. https:// doi.org/10.1007/s11367-017-1352-5

Russell KR, Wigley TB, Baughman WM, Hanlin HG, Ford WM (2004) Responses of southeastern amphibians and reptiles to forest management: a review. In: Southern forest science: past, present, and future. Gen. Tech. Rep. SRS-75. U.S. Department of Agriculture, Forest Service, Southern Research Station, Asheville, NC, pp 319334

Swanson ME, Studevant NM, Campbell JL, Donato DC (2014) Biological associates of early-seral pre-forest in the Pacific Northwest. Forest Ecol Manag 324:160-171. https://doi.org/10. 1016/j.foreco.2014.03.046

Teixeira RFM, Maia de Souza D, Curran MP, Antón A, Michelsen O, Milà i Canals L (2015) Towards consensus on land use impacts on biodiversity in LCA: UNEP/SETAC Life Cycle Initiative preliminary recommendations based on expert contributions J Clean Prod 112, Part 5 doi:https://doi.org/10.1016/j.jclepro.2015.07.118

thinkstep AG (2012) GaBi: software and database contents for Life Cycle Engineering. Stuttgart

UNEP-SETAC Life Cycle Initiative (2016) Global guidance for life cycle impact assessment indicators, vol 1. United Nations Environment Programme, Nairobi

US Department of Transportation and US Department of Commerce (2015) 2012 economic census-transportation-commodity flow survey. EC12TCF-US

Vellend M (2017) The biodiversity conservation paradox. Am Sci 105: 94-101. https://doi.org/10.1511/2017.105.2.94

Verschuyl JP, Hansen AJ, McWethy DB, Sallabanks R, Hutto RL (2008) Is the effect of forest structure on bird diversity modified by forest productivity. Ecol Appl 18:1155-1170. https://doi.org/10.1890/070839.1

Warrington BM et al (2017) Forestry best management practices relationships with aquatic and riparian fauna: a review. Forests 8:331

Wernet G, Bauer C, Steubing B, Reinhard J, Moreno-Ruiz E, Weidema B (2016) The ecoinvent database version 3 (part I): overview and methodology. Int J LCA 21:1218-1230. https://doi.org/10.1007/ s11367-016-1087-8

Publisher's note Springer Nature remains neutral with regard to jurisdictional claims in published maps and institutional affiliations. 